\title{
RUPTURE OF AORTIC ANEURYSMS INTO THE GUT
}

\author{
BY
}

\author{
G. A. GRESHAM AND H. R. M. JOHNSON \\ From the Department of Pathology, University of Cambridge
}

Received September 9, 1958

Rupture of an aortic aneurysm into the gut is uncommon. The duodenum is most often involved, stomach and jejunum being next in order of frequency. Involvement of the œsophagus is now decidedly rare probably due to the declining incidence of cardiovascular syphilis.

We report three cases of aortic aneurysm; two in the abdomen ruptured into the second part of the duodenum and one in the thorax into the esophagus. A fistula between aorta and inferior vena cava was also present in one of the cases with an abdominal aneurysm; in the other the wall of the inferior vena cava was partially eroded.

\section{CASE REPORTS}

Case 1. This woman, aged 84, was found dead at home: she had, apparently, been in good health for the past thirty years.

Necropsy (P54.086). A small saccular aneurysm $(3.0 \mathrm{~cm}$. diameter) arose from the very atheromatous aorta $7 \mathrm{~cm}$. distal to the coeliac axis. It contained thrombus and communicated with the second part of the duodenum through a hole, $0.5 \mathrm{~cm}$. diameter, at the duodenum end (Fig. 1). The inferior vena cava was stretched over the right lateral aspect of the aneurysm and was adherent to it; the initimal surface was discoloured at this point (Fig. 2). The stomach and duodenum contained about $700 \mathrm{ml}$. of blood clot. The stomach and transverse colon, together with part of the greater omentum, lay in a hernial sac in the left hemithorax. The hernial ring $(30 \times 10 \mathrm{~cm}$.) did not appear to have caused vascular obstruction to its contents. A small right indirect inguinal hernia contained a short loop of apparently normal terminal ileum. The heart weighed 195 grammes.

No important abnormality was found in any other organ system.

Case 2. This man, aged 65, had complained of bilateral lumbar pain for three weeks and the cause of this was not determined. No abnormal pulsation was noted in the legs. A radiograph of the pelvis showed the changes of Paget's disease of bone. He was found dead in bed at home.

Necropsy (P58.086). A saccular aneurysm $(8 \times 6 \times 5 \mathrm{~cm}$.) arose from the right side of the grossly atheromatous aorta immediately above the bifurcation. It contained thrombus and communicated with the second part of the duodenum through a hole $(2 \times 1 \mathrm{~cm}$.) $1 \mathrm{~cm}$. below the ampulla of Vater (Fig. 3). Posteroinferiorly it joined the inferior vena cava through a hole approximatley $2 \mathrm{~cm}$. diameter (Fig. 4). The stomach contained a litre of blood clot and a further $600 \mathrm{ml}$. of blood and clot were found in the upper part of the small gut. A small quantity of blood clot was seen on either side of the aneurysm retroperitoneally. A small abscess, approximately $1 \mathrm{~cm}$. diameter, was found in the antero-inferior wall of the aneurysm adjacent to the duodenal hole. The heart weighed 295 grammes.

Apart from evidence of Paget's disease in the right ilium there was no important abnormality elsewhere.

Histological examination of the wall of the aneurysm showed atheroma and medionecrosis. One section included an abscess containing streptococci. A section of the ilium confirmed the diagnosis of Paget's disease.

Case 3. This man, aged 69, had been admitted to Bedford Hospital 6 months previously with melæna and pain between the shoulders. He had had chest pain for a month before which was attributed to cardiac ischæmia. An aneurysm of the thoracic aorta was found; the Wassermann and Kahn tests were positive. A barium meal suggested the presence of a duodenal ulcer. He was readmitted four months later with cough and shortness of breath and improved following digitalization. He suddenly collapsed at home a month later after vomiting blood. On readmission to Bedford Hospital he was dyspnoeic and cyanosed with atrial fibrillation, and died a few hours later. 


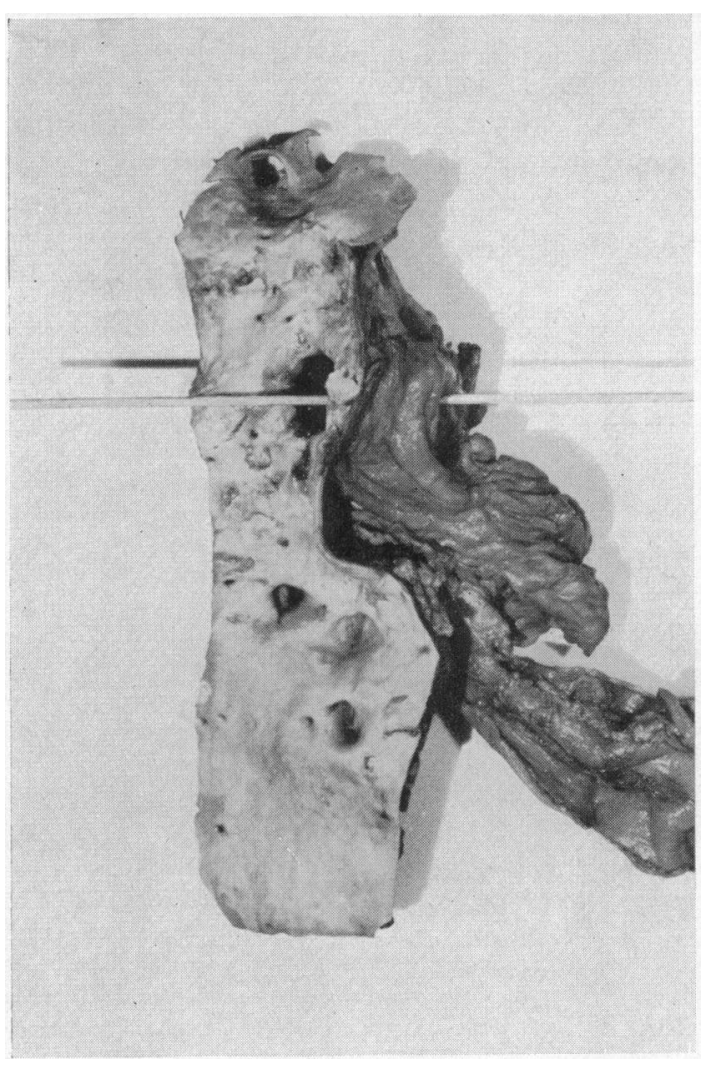

FIG. 1.-Aorta on left, duodenum on right, rod in fistula (Case 1).

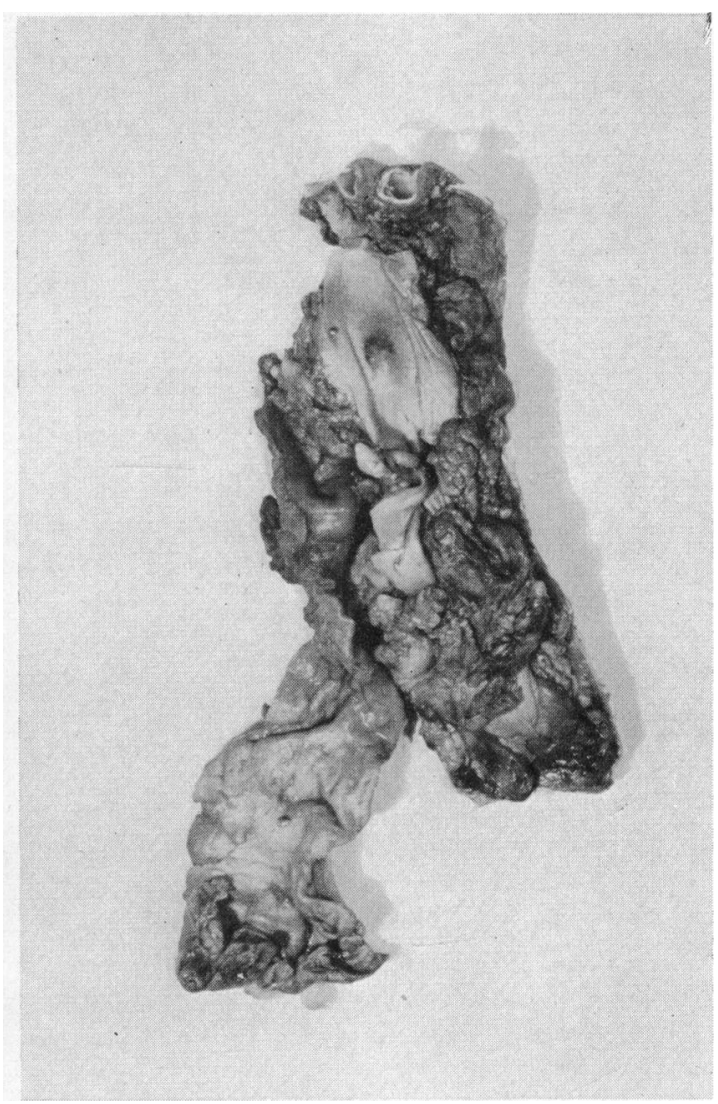

Fig. 2.-Discoloration of inferior vena cava adjacent to aneurysm (Case 1).

Necropsy (Bedford 1505). A fusiform aneurysm $10 \mathrm{~cm}$. long was present in the dilated descending thoracic aorta. The intimal surface was wrinkled and the lumen contained adherent recent thrombus. The aneurysm was adherent to the œsophagus, with which it communicated through a hole $2 \mathrm{~cm}$. diameter (Fig. 5). The rest of the aorta showed severe atheroma. The heart was dilated but not grossly hypertrophied; the aortic valve was normal. No evidence of peptic ulceration was found in stomach or duodenum. Bronchopneumonic changes were seen in the right lower lobe. No important abnormality was found elsewhere, nor was there any other evidence of syphilis.

Histological examination of the thoracic aorta showed gross disorganization of the media with patchy cellular infiltration. There was also cellular infiltration, mainly by plasma cells, in the adventitia. The appearances were those of syphilitic aortitis.

\section{Discussion}

Rupture of aortic aneurysms is a not infrequent cause of sudden death usually leading to hæmorrhage into serous cavities or extra-peritoneal tissues. In contrast hæmorrhage into a viscus from such an aneurysm is rare. Those parts of the gut most frequently involved lie in close proximity to the aorta.

Involvement of the œsophagus is probably the least uncommon: Lemann (1916) reviewed 592 aneurysms of the thoracic aorta and found fifty that had ruptured into the osophagus; none had ruptured into the stomach. More recently Hirschowitz and Bagg (1951) found five such cases reported in the previous twenty-seven years and two others have been added, one by 
Callenda and Uricchio (1953) and one by Salmons (1954). Thoracic aortic aneurysms are frequently due to syphilis; it is likely that rupture into the asophagus will become rare as the incidence of cardiovascular syphilis declines.

However, atheromatous aneurysm of the abdominal aorta is likely to become more common as the average expectation of life increases. Such aneurysms rupturing into the gut do so most often in the duodenum. Rottino (1943) collected 32 reported examples; a further review by Roll and Caudell (1956) revealed 24 others to which they added two more. Skromak et al. (1957) collected 53 examples, reported since 1843, of aneurysms rupturing into the gut. They give the age, sex, and ætiology of most of the cases and added two more of their own. We have been able to add to these, eight cases of Hirst and Affeldt (1951), one of Renner and Sindelar (1953), one of Roll and Caudell (1956), one of Ross and Pheils (1957), and three of our own.

The site of rupture in 54 of these 69 cases was the duodenum, 42 into the third part, 4 (including our two cases) into the second part, and in 8 the precise site is not stated. Of the

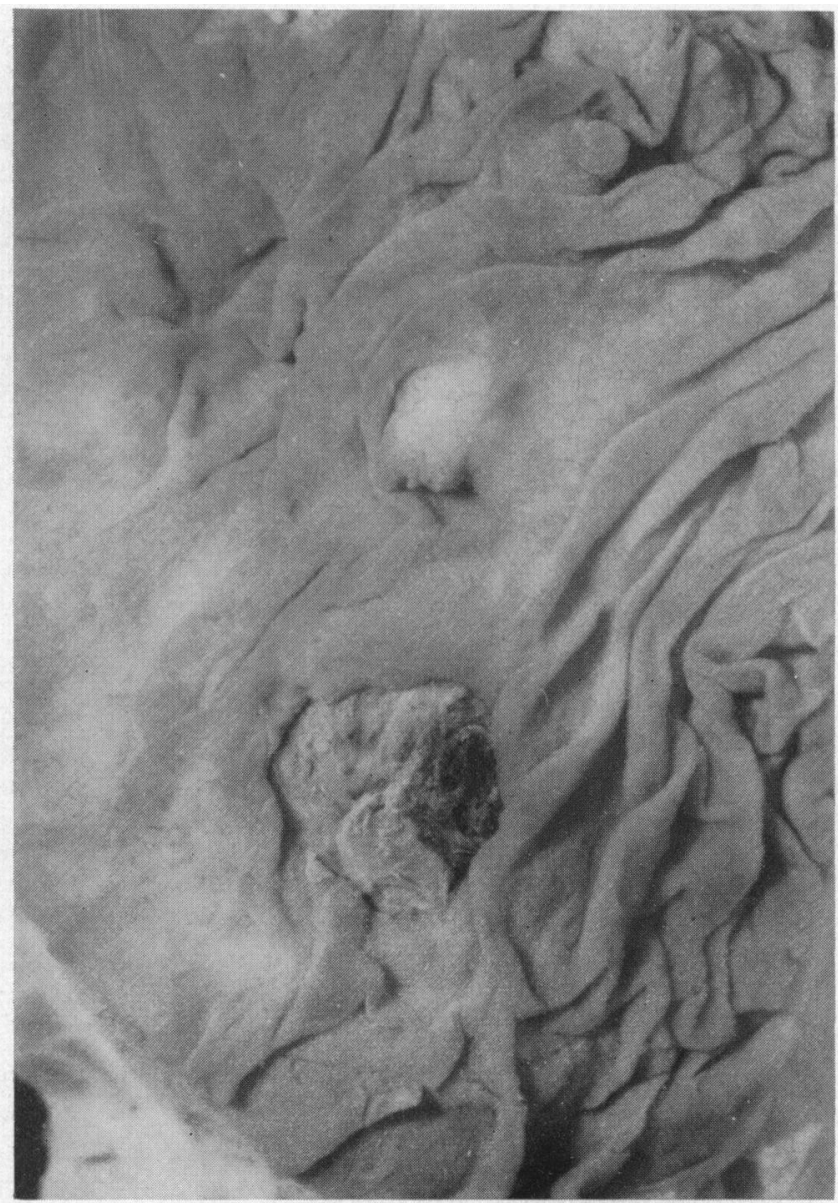

FIG. 3.-Duodenal fistula with ampulla of Vater above (Case 2).

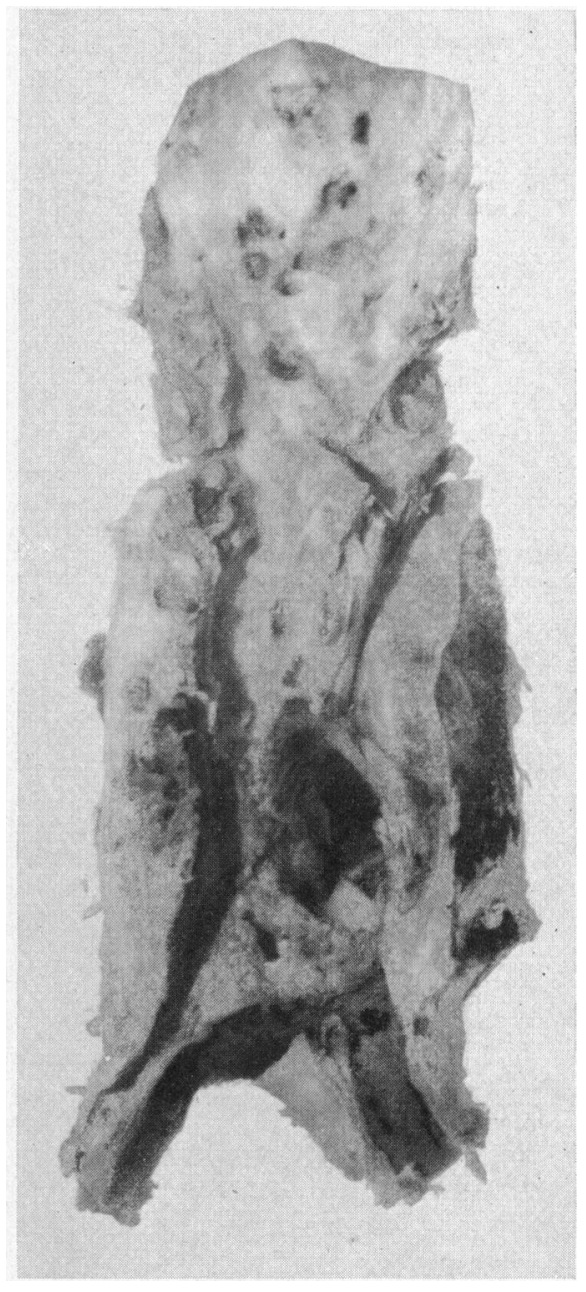

Fig. 4.-Abdominal aorta and its bifurcation opened posteriorly to show arterio-venous aneurysm between aorta and inferior vena cava (Case 2). 
remaining cases seven ruptured into the stomach, five into the jejunum, and three into the ileum.

Arteriosclerosis was the cause of the aneurysm in 42 cases, syphilis in 12, tuberculosis in 4 , "mycosis" in 4, and in 9 it was not stated; some had a double ætiology. In the 24 cases prior to 1930 eleven were arteriosclerotic $(46 \%)$; since 1930, 32 of the 45 cases have been due to arteriosclerosis $(71 \%)$.

Fifty-three of the cases were men. The greatest incidence is in the fifth, sixth, and seventh decades but the average age of the cases is rising; prior to 1930 it was 49.9 years, since that date it is 62.5 years. This parallels the rise in the incidence of arteriosclerosis as the cause of aneurysm.

Both cases of abdominal aneurysm here reported showed involvement of the inferior vena cava. Case 1 showed a roughening of the intima of the vena cava but no perforation: this is similar to the case described by Ross and Pheils (1957). Case 2 showed an arteriovenous aneurysm between

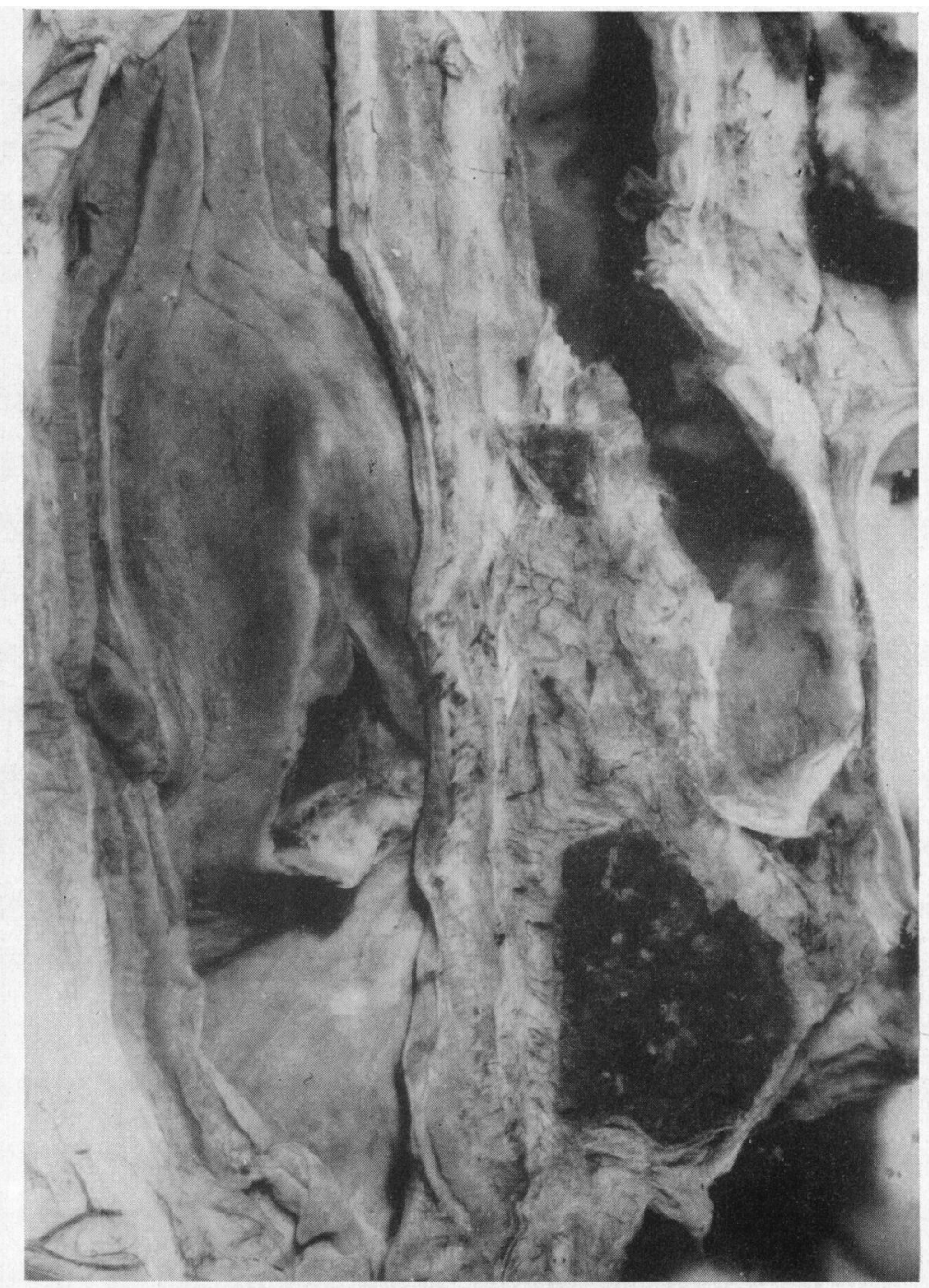

Fig. 5.-Hole in the œsophagus at level of the tracheal bifurcation (Case 3). 
inferior vena cava and aorta. The remarkable feature was the dearth of physical signs that might have been expected. Boffi (1955) states that spontaneous rupture of an aortic aneurysm into the inferior vena cava is an exceptional event: he reviewed the world literature since 1831 and found 25 cases and added one of his own. Buzzi et al. (1957) describe a case, but were only able to discover 10 similar reported cases, all of them included by Boffi in his review. Thus there are only 28 recorded cases including our Case 2. As far as we can discover no case has been described previously in which there has been rupture both into the gut and inferior vena cava.

The mechanism of rupture of an aortic aneurysm into a mobile structure, such as gut, is not easy to understand. The duodenum and œsophagus are rather less free to move than other parts and hence might be more likely to undergo pressure atrophy from an adjacent aneurysm. Such an argument cannot be applied to stomach and jejunum. Some anchoring mechanism probably takes place and fixes the gut to the aneurysm before rupture occurs. This may be caused by a small hæmorrhage leading to an inflammatory reaction with fibrosis though such a mechanism is difficult to prove after rupture has occurred. The presence of hæmosiderin between the gut and aneurysm may indicate hæmorrhage either before or after adhesion between gut and aneurysm has occurred.

Such aneurysms as we have described are now of more than academic interest. Recent rapid advances in arterial surgery make extirpation and grafting a possibility provided that early diagnosis can be achieved.

\section{SUMMARY}

Three examples of rupture of aortic aneurysms into the gut are described. Syphilis was the cause of the aneurysm that ruptured into the csophagus and arteriosclerosis of the two that ruptured into the second part of the duodenum.

The two abdominal aneurysms involved the inferior vena cava and in one there was an arteriovenous fistula. The mechanism of rupture is discussed.

We are grateful to Dr. A. M. Barrett for his encouragement and permission to use the necropsy reports, and to Dr. J. C. Valentine for the necropsy report of the Bedford case. Case 1 and Case 2 are published by permission of Her Majesty's Coroners for Cambridgeshire. Dr. G. K. S. Roberts kindly translated the Italian paper.

\section{REFERENCES}

Boffi, L. (1955). Chir. E. Pat. Sper., 3, 73.

Buzzi, A., Henry, J., and Rossi, D. (1957). Prensa med. Argent., 44, 1527.

Callenda, D. G., and Uricchio, J. F. (1953). J. Amer. med. Ass., 153, 548.

Hirschowitz, B. I., and Bagg, L. (1951). Gastroenterology, 18, 361.

Hirst, A. E., and Affeldt, J. (1951). Gastroenterology, 17, 504.

Lemann, I. I. (1916). Amer. J. med. Sci., 152, 210.

Renner, W. F., and Sindelar, J. (1953). J. Amer. med. Ass., 153, 102.

Roll, W. A., and Caudell, W. B. (1956). A.M.A. Arch. Surg., 72, 295.

Ross, C. F., and Pheils, M. T. (1957). Gastroenterology, 32, 756.

Rottino, A. (1943). Amer. Heart J., 25, 826.

Salmons, J. A. (1954). Gastroenterology, 27, 474.

Skromak, S. J., O’Neill, J. F., Ciccone, E. F., and Snyder, R. J. (1957). Gastroenterology, 33, 575. 